\title{
The Mating BehaVIOR OF IGUANA IGUANA
}

A CONDENSED VERSION OF A STORY BY GORDON H. RODDA

\section{Introduction}

The green iguana, Iguana iguana, is well suited to interpopulational comparisons of its mating behavior because the species is widely distributed and easily observed. In addition to being diurnal and sedentary, the iguana mates in exposed locations (in trees) and its mating behavior appears to rely almost exclusively on vision, a modality readily monitored by human observers. Dugan (1980; 1982b) described mating behavior of green iguanas from a small island (Flamenco) in the Gulf of Panama. Males displayed with characteristic headbobs, then jockeyed for possession of exclusive mating territories. Mating territories included no resources needed by females; they provided only space to mate. Precopulatory females visited several territories. One to four females selected the mating territory of each large male, and over $90 \%$ of the females eventually copulated there. Mediumsize males rarely controlled territories with a female. Small males (which resemble females morphologically) obtained a few copulations by entering territories undetected and forcing copulations when the resident male was occupied or out of view.

The major goals of the present study were to provide a relatively complete record of mating behaviors in the green iguana and to compare the results of this study with the study of Panamanian iguanas by Dugan. In the llanos of Venezuela, iguanas often inhabit areas with scattered trees and discontinuous canopy, facilitating visual observation and recognition of individual iguanas. Dugan studied a large number of mating territories, each for short periods of the day. Dugan never observed males to mate more than once per day or to eat during the mating season. However, because she reported that feeding takes about 20 min per day

Gordon H. Rodda, National Ecology Research Center, 4512 McMurray Ave., Fort Collins, Colorado, 80525 and that copulation lasts about $7 \mathrm{~min}$, it is possible that these behaviors might have occurred when the animals were not under observation. Also, Dugan was not able to identify the individual female iguanas under study. By subjecting a smaller number of known individuals to continuous scrutiny, I was able to unequivocally determine the frequencies and context of selected rare, but potentially significant, behaviors. In combination with Dugan's work, these data provide the most detailed observations available for the mating behavior of a reptile.

This monograph is divided into four parts, each with a "Results" and "Discussion." To provide a context, the first short section, "Nonbreeding Behavior," describes typical green iguana behavior outside the breeding season. The second section, "General Mating Behavior," gives a general description of reproductive behaviors leading to copulation. (Some postcopulatory reproductive behaviors are described in Rodda (1990) and Rodda and Grajal (1990).) The third and fourth sections focus on two aspects of mating that present unresolved theoretical problems: "Forced Copulations" and "Female Dominance Relations." The methods section below describes the methods used throughout.

\section{Materials and Methods}

My field assistants and I observed iguanas in the central llanos of Venezuela from June 1982 to January 1984. A blind was set up 50-100 m from 2-8 mating territories at each of three sites: El Frio, Guacimos, and Masaguaral. The areas chosen for observation had iguanas bearing sufficient natural markings that it was not necessary to capture iguanas for individual recognition (Rodda et al., 1988). The primary character used for individual recognition was the morphology of the damaged or unusual dorsal-crest scales. Crest scales are visible from 
both sides of the animal and each scale was distinguishable on the basis of length (14 character states), attitude (6 states), curvature (6 states), and tip type (6 states; Rodda et al. 1988). Color pattern, tail regrowth, and other morphological idiosyncrasies provided supplemental recognition characters.

The three major study sites were observed periodically throughout the year. A fourth, "La Guanota," was observed opportunistically from a darkened automobile "blind" for information on gross population movements. At Guacimos, one mating territory was observed from before dawn until after dark throughout the 1983 copulation season to provide an uninterrupted record of mating behaviors. To verify that the results from this intensively monitored territory were representative, seven other Guacimos territories were scanned periodically throughout the day from the same blind. In addition, the Masaguaral and El Frio blinds each were used for several hours a day periodically during the 1982 and 1983 mating seasons. The Masaguaral site included two mating territories and was monitored almost every day during mating. At El Frio, the two territories within the study site were monitored for a few days each month. In sum, one Guacimos territory was observed continuously and eleven more territories (at Guacimos, Masaguaral, and El Frio) were observed with varying degrees of thoroughness for one or two mating seasons. The omission of a site from the results simply reflects an inadequate data base from the omitted site with reference to the question at hand. All contrary results are noted.

Subjecting one site to continuous observations for an entire mating season increases the opportunity for detecting rare but significant events such as copulations. The disadvantage of this technique is that a small number of individuals are sampled repeatedly. When it was possible to quantify the total amount of the variance contributed by individual identity, the contribution usually was found to be less than $15 \%$. The most difficult problem of sample size arose in the analysis of dominant male behavior, because only one dominant male was monitored continuously. In this case, the general applicability of conclusions is based on similarity between the intensively monitored male's behav- ior and that of the 11 other territorial males that were monitored less intensively.

\section{Study Sites}

The Guacimos, La Guanota, and Masaguaral sites were located in the mixed savanna/woodland of the central llanos of Venezuela (habitat described in Neville, 1972). The Guacimos site $\left(8.575^{\circ} \mathrm{N}\right.$, $67.605^{\circ} \mathrm{W}$ ), was observed during all daylight hours from 30 November to 24 December 1983, and at varying hours of the day from 4 October 1983 to 12 January 1984 , for a total of $756.5 \mathrm{~h}$. Because iguanas sleep throughout the night (Flanigan, 1973), the more than 40,000 behaviors recorded at Guacimos are a complete record for the copulation season and a comprehensive record for several weeks immediately preceding and following the copulation season. One hundred twenty-three individual iguanas were seen at the Guacimos site during our observations.

The Masaguaral site $\left(8.564^{\circ} \mathrm{N}, 67.588^{\circ} \mathrm{W}\right)$, about $3 \mathrm{~km} \mathrm{SE}$ of Guacimos at the edge of a seasonal marsh, was observed at varying hours on 258 days from 12 September 1982 to 23 December 1983 , for a total of $527.6 \mathrm{~h}$. Almost all of the observations included the $2 \mathrm{~h}$ preceding sunset, an interval that yielded the greatest number of observable interactions among the iguanas. At Masaguaral we saw a total of 65 individual iguanas during 1982 and 73 during 1983. About half of the observations (138 days, $278.4 \mathrm{~h}$ ) occurred during OctoberDecember, the months of mating activity.

The La Guanota site $\left(6.92^{\circ} \mathrm{N}, 67.52^{\circ} \mathrm{W}\right)$ was located on the ranch "Hato La Guanota." The vegetation was similar to that in the above-mentioned study sites, but the trees were not near a water body. The iguanas were viewed for $1-2 \mathrm{~h}$ on each of 7 visits to the site from November 1982 to September 1983 (14 individuals seen).

The El Frio site $\left(7.812^{\circ} \mathrm{N}, 68.897^{\circ} \mathrm{W}\right)$ was in a narrow gallery forest among the savannas of the low llanos on the ranch "Hato El Frio" (habitat described by Tamayo, 1964). The study trees, at the edge of an impounded stream, were observed at varying hours on 41 days between 22 September 1982 and 30 December 1983, for a total of $91.7 \mathrm{~h}$. About half of the observations ( 21 days, $53.3 \mathrm{~h}$ ) occurred during the mating season months of 
October-December. We saw 28 individual iguanas in 1982 and 37 in 1983.

\section{Behavioral Methods}

Four observers attempted to record all copulations, interactions, and movements within the study sites (typically a space of about $10 \times 10 \times 10 \mathrm{~m}$ ). Headbob displays were recorded whenever possible. The fraction of the displays that were not recorded was estimated by comparing the written record with cine films of 44 sequences of interactions filmed during the peak of mating activity. Slow motion analysis of the films revealed that all copulations, interactions, and movements in the sample had been recorded, but only $66 \%$ ( 40 out of 61 ) of the displays had been noted. The estimated display totals reported in this paper are extrapolations from the tabulated counts.

At the beginning of the study, a few animals were captured and marked with colored beads, but these animals subsequently exhibited aberrant behavior (Rodda et al., 1988). Consequently, capture and marking was discontinued and all adult iguanas were recognized individually by their unique patterns of color and crest-scale damage or loss (Rodda et al., 1988). For the identifications made by more than one observer, interrater agreement exceeded $99.7 \%(\mathrm{~N}>1000)$.

The relative sizes of individuals were determined by noting which animal of a pair was larger whenever two individuals rested on a branch perpendicular to the observer. At Guacimos these pairings yielded 304 comparisons that were related to absolute dimensions from measurements of nine individuals captured at the conclusion of the study. The nine measured animals included the smallest and largest resident females as well as the second largest male; thus, the sizes of all of the residents at Guacimos are fairly precisely known because they are anchored by absolute measurements. The sizes of iguanas at the other sites are less precisely known, but each animal was readily classified as small, medium, or large based on their approximate absolute size based on direct observation.

Sexing was based on external dimorphisms; dorsal-crest spines, head size, and femoral pore size are larger in males (Dugan, 1980; Fitch and Henderson, 1977 Rodda, 1991). No nominal "males" became gravid and all nominal "females" did so.

The positions of each iguana in a tree were recorded with reference to one of the mapped perches in the study site (207 perches were mapped in the intensively monitored tree at Guacimos). Absolute distances between animals were computed only for Guacimos, where the tree and its environs were photographed at a distance of $30 \mathrm{~m}$ from 18 equally spaced positions $\left(0^{\circ}-340^{\circ} \times 20^{\circ}\right)$. A calibrated reference rod of known dimensions was central located in each photograph.

Operational Definitions. - "Perch," "approach," "interaction," and "copulation/ attempt" have special meanings in this paper. A "perch" was an iguana-size segment of a tree limb or branch that was habitually used by resting iguanas. Initially, each limb was divided into 10,20 , or 100 equal sectors, depending on the limb's absolute length. Records of the positions of resting iguanas were accumulated until clusters of positions became clearly evident for each limb. Perches were based on the modal position within clusters, with the restriction that each perch was sufficiently distant from the immediately adjacent perch that occupancy of one would not physically preclude occupancy of the adjacent perch.

An "approach" was a movement of an iguana from a more distant site to within $2 \mathrm{~m}$ of a specific iguana.

An interaction was said to have ended when either (1) the animals were no longer adjacent, or (2) $5 \mathrm{~min}$ had elapsed without any noticeable action. If the interaction involved more than two iguanas and the roles of the various iguanas were unclear the interaction was not scored. This occurred primarily when iguana densities were very high, so that the absolute number of interactions reported at high densities is an underestimate. Each interaction was scored on a scale of 1-5 for its outcome, with a "1" indicating that the approacher had fled rapidly from the site of the interaction (usually leaving the tree), and " 5 " indicating that the approached animal had fled rapidly (usually by jumping out of the tree). The interactions scored as 1 or 5 were categorized as "high intensity"; the other interactions were termed "low intensity." A 
"2" indicated that neither animal moved, a "3" indicated a slow or delayed upward movement of the approached animal (the modal response), and a " 4 " indicated a rapid but short distance movement of the approached animal (usually a displacement of a few perches.

A "copulation attempt" occurred when a male mounted another iguana. In two cases out of 250 a male mounted another male, which I assumed to be a mistake, because the attempt was quickly broken off and no other evidence of homosexual behavior was seen.

I use "mating" season to include the date of all behaviors preliminary to and including copulation; "copulation" season to include only the dates from earliest to latest copulation; and "breeding" season to include the seasons of both mating and postzygotic parental care (in this case, through oviposition).

\section{Nonbreeding Behavior Results}

The behavior of iguanas outside the mating season differed from that seen during the mating season in three major ways: (1) during normal waking hours outside the breeding season, adult iguanas spent the majority of the time immobile, apparently resting; 2) their interactions involved fewer high intensity displays; and (3) their day to day movements were somewhat nomadic, with less attachment to a specific sleeping tree.

Daily ACTIVITY PATTERN. - When sleeping, the iguanas usually lay horizon. July (23\% of 509 sleep site selections) or with head up ( $75 \%$ of 509). Of 115 horizontal perch uses, I recorded about twice as many (75 vs 40$)$ with the head pointed away from the base of the limb as pointed toward the limb base. Although iguanas prefer to sleep at the ends of branches and they prefer branches that extend over water, they showed no preference for specific branch angles or diameters from $1.5 \mathrm{~cm}$ diameter vines up to about $18 \mathrm{~cm}$ diameter limbs).

Iguanas slept throughout the night, as indicated by (1) continuously closed eyes, (2) greater arousal thresholds, and (3) continuous immobility. On 59 nights at Guacimos we observed 697 iguanas positions both at dusk and the following dawn. None of the iguanas changed perches. Iguanas became immobile at dusk even if they were in the middle of social interactions when it became dark. The only circumstance in which we observed iguanas sleeping on top of each other was when the top individual had been climbing over the other at nightfall. On one of three such occasions a pair of iguanas were in the midst of a violent fight at dusk. The fight was not resumed at dawn; instead the iguanas disengaged and basked separately.

The iguanas opened their eyes before sunrise, buy they did not move until direct sunlight provided an opportunity for them to bask. In emergent trees, this produced a peak of activity at sunrise. For example, from 5 to 20 November 1983 at the Guacimos site I recorded 92 movements in the 15 min interval that included sunrise, compared to only 9 movements during the $15 \mathrm{~min}$ interval $1 \mathrm{~h}$ later when the iguanas were in the midst of basking. I noticed, but did not quantify, exceptional wariness among the iguanas early in the day; flight distances of iguanas in trees seemed to be about $90 \mathrm{~m}$ at dawn compared to 50-60 $\mathrm{m}$ after the iguanas warmed up.

The iguanas routinely basked in a head down position. I was unable to determine if this was related specifically to basking or was simply a result of their morning descent of the tree. As they warmed, the iguanas made a series of short, intermittent moves toward the base of their sleeping tree.

I found it difficult to keep track of individual iguanas as they were foraging on the ground and in nearby trees and shrubs Therefore, it was not possible to quantify the average time per day spent foraging. However, it was evident that much, if not most, of the foraging occurred on ground herbs and low shrubs. The iguanas quickly retuned to the trees whenever humans or foxes approached to within 100-200 m, but it was uncommon for undisturbed iguanas to be high in trees during midday. During midday, the iguanas spent the majority of their time resting. I never saw individuals foraging for a period of greater than $30 \mathrm{~min}$.

Unless disturbed by predators, the iguanas began returning to their sleeping trees two to three hours before sunset. Large iguanas usually arrived before the smaller ones $(\mathrm{F}=6.16 ; \mathrm{df}=1,25 ; \mathrm{P}=$ 0.020 ), but arrival times did not differ between the sexes $(F=0.61 ; d f=1,25 ; P=0.44)$. The mean arrival time for the 25 iguanas present at Guacimos 


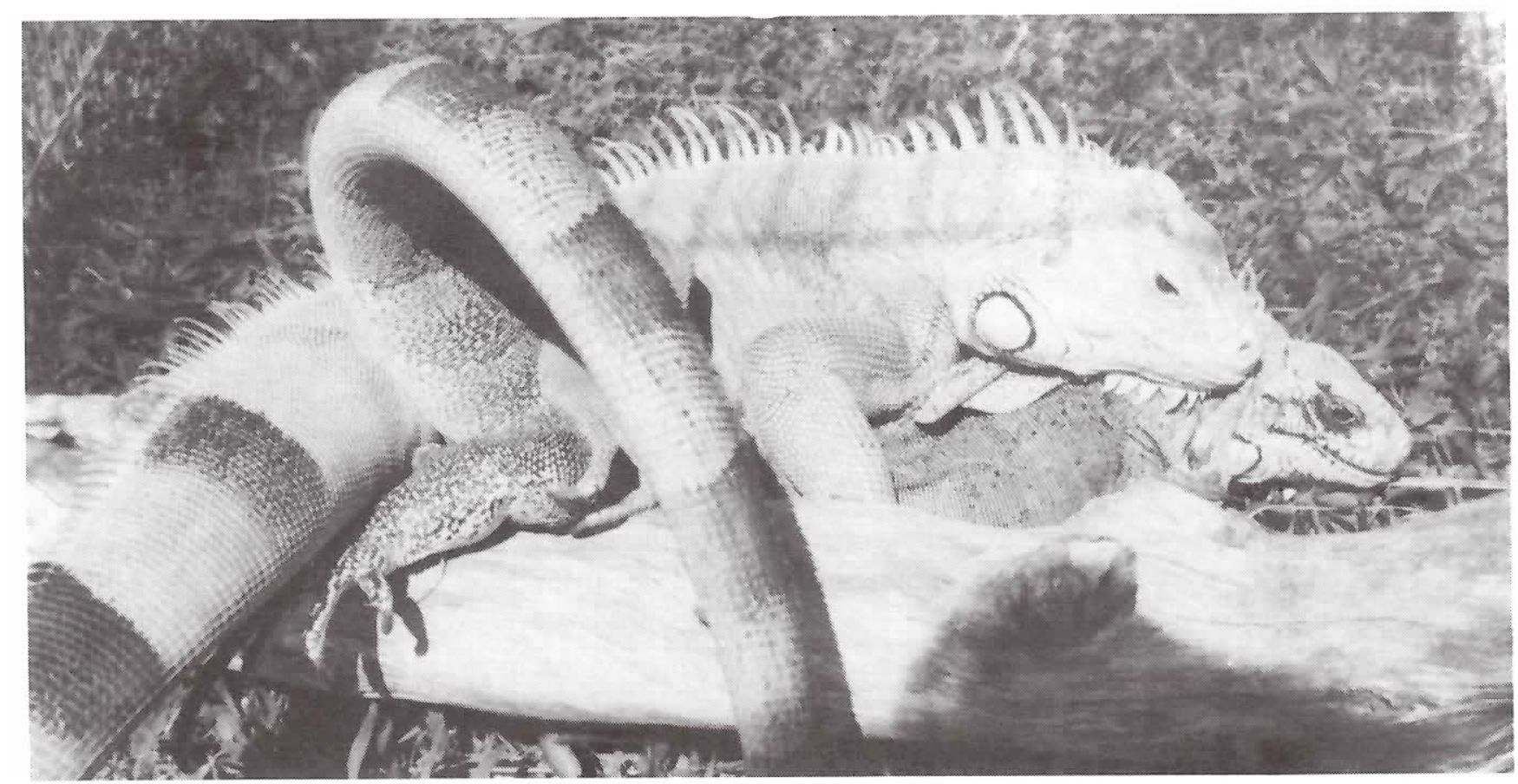

Breeding couple, Iguana iguana, in captivity. Photograph: Deborah Neufeld

in October 1983 (this sample is characteristic of nonmating conditions) was $2.3 \mathrm{~h}$ before sunset for large iguanas and $1.7 \mathrm{~h}$ before sunset for small iguanas (i.e., $<350 \mathrm{~mm}$ snout-vent length (SVL)). The time of their last move of the day (to sleeping perches) did not vary between sizes or sexes.

Almost all interactions between nonbreeding iguanas were of low intensity and the outcome usually was predictable on the basis of which iguana was higher in the tree. Individual identities or relative sizes seemed unimportant. A typical afternoon interaction was initiated by an iguana climbing a branch at a slow pace until it reached a point immediately below a resting iguana. In a sample of 226 nonbreeding interactions, the approaching animal gave a headbob in $31 \%$ of the cases and the approached animal gave a headbob in $41 \%$ (the difference in these proportions was not significant.

In nonbreeding season interactions $(\mathrm{N}=290)$ the modal outcome (33\%) was no response (i.e., both iguanas remained stationary). However, if an iguana did move, it was much more likely that the animal that was initially stationary would move ( $55 \%$ vs $12 \%$ ). In about $5 \%$ of the cases, the higher animal did not respond to being approached, but the lower animal eventually continued on its way by walking across the back of the higher iguana. The usual response of the walked-upon iguana was to "scratch" or tail arch at the other animal as it passed by, or to bob after the interaction. A "scratch" consisted of swinging the forelimb in the general direction of the other iguana. One or both forelimbs might be used. These movements appeared to be ritualized, as the nominal recipient rarely was touched by the "scratching" animal and no damage was ever done.

I was unable to discern a hierarchy among the iguana individuals based on their success in convincing other iguanas to move ahead when they were ascending the study trees outside of the breeding season (see also "Female Dominance Relations"). At least three factors would make it difficult to identify individual relations if such exist outside the breeding season: (1) a majority of interactions did not have a decisive outcome, (2) the physical asymmetry in interactions (the higher animal usually moves) tended to obscure individual relations, and (3) as iguanas wander more during the nonbreeding season, there are few opportunities for two individuals to interact repeatedly. This wandering habit not only makes it unlikely that specific dyads would be observed repeatedly, but it also minimizes the opportunities for iguanas to develop consistent dominance relationships among themselves. 
POPULATION CHARACTERISTICS. - Iguana densities differed among the sites in Venezuela and from the densities in Panama reported by Dugan (1980:32-37; 1982a; 1982b). Unfortunately, it was not appropriate to quantify the densities at the sites I studied in units of individuals per ha, as reported by Dugan. Dugan's site was a small, forested, coastal island over which the iguanas were relatively evenly dispersed. My sites, like most iguana habitats, were strips of trees along water courses. The iguanas foraged in adjacent shrubs and on the ground in the surrounding savannas, but they took refuge almost exclusively in the narrow tree corridors that rarely exceeded the canopy of one tree in width. Iguanas rarely ventured more than $50 \mathrm{~m}$ from riparian shrubs and most iguana activity occurred within $15 \mathrm{~m}$.

At three of four sites, population turnover (daily percent of study population changing sleeping perch to a place outside of the monitored area) was relatively higher outside of the copulation season, while El Frio exhibited near-zero population turnover at any time. At La Guanota, all iguanas abandoned the trees used for breeding near the beginning of the rainy season but returned to this area by the middle of the rainy season. At all sites, males and females had different patterns of movements, with females changing locations more often

Table 1. - Nonmating season population sizes of iguanas in the territories shown in Figure 1. Letters in parentheses are territories in Figure 1.

\begin{tabular}{|c|c|c|c|}
\hline & El Frio & Massguaral & Guacimos \\
\hline \multirow{8}{*}{$\begin{array}{l}\text { Mean numbers of sleeping } \\
\text { iguanas }\end{array}$} & $1.8(\mathrm{~A})$ & $2.3(\mathrm{C})$ & $10(\mathrm{AF})$ \\
\hline & $4.8(P)$ & $3.2(\mathrm{AZ})$ & $4.5(A G)$ \\
\hline & & & $8(\mathrm{AL})$ \\
\hline & & & $7(B F)$ \\
\hline & & & $4.5(\mathrm{BJ})$ \\
\hline & & & $5.5(\mathrm{BZ})$ \\
\hline & & & $17(C)$ \\
\hline & & & $12.4(\mathrm{H})$ \\
\hline Total for site ${ }^{\star}$ & 6.6 & 6.4 & $\sim 80$ \\
\hline $\begin{array}{l}\text { Est. area of sleeping trees } \\
\text { (hectares (ha)) }\end{array}$ & 0.02 & 0.01 & 0.035 \\
\hline Est. adjacent foraging area (ha) & 0.10 & 0.05 & 0.175 \\
\hline Length of shoreline $(\mathrm{km})$ & 0.021 & 0.01 & 0.035 \\
\hline Linear density (iguanas/km) & 314 & 640 & 2285 \\
\hline $\begin{array}{l}\text { Areal density (iguanas/ha) } \\
\text { (area is sum of sleeping and } \\
\text { foraging area) }\end{array}$ & 55 & 107 & 364 \\
\hline
\end{tabular}

than males throughout the year.

Females were more numerous than males (average female/male sex ratios among nonmating iguanas measured at dusk: 3.4 at El Frio, 2.3 at Masaguaral, 2.3 at Guacimos). Males were slightly larger than females (adequate data are available only for Guacimos during the mating season: male/female length ratio $=1.1$ ).

\section{Discussion of Nonbreeding Behavior}

Iguanas usually find plenty of edible leaves in their immediate vicinity (Rand, 1978). Moreover, an iguana's gut has room for only modest additions each day, as passage times are lengthy (average 6.9 days for this population; D. Brust, pers. comm.). Dugan's (1982b) estimate of daily foraging time of 20 min is consistent with the 30 min maximum that I observed. Unlike the large insectivorous lizards in the study areas (e.g., Tupinambis), iguanas readily interrupted their foraging in response to distant approaches of a potential predator (Rodda and Burghardt, 1985). Finding enough to eat does not appear to be a major problem for iguanas, but leaves have relatively little extractable food energy. Thus, it is not surprising that these lizards conserve energy (Dugan and Wiewandt, 1982). Most of their day is devoted to basking. Nonbreeding iguanas bask for about 4 hours in their sleeping tree in the morning and another 2-3 hours in the afternoon. They arc immobile for most of the time that they are out of their sleeping tree. Stamps (1983) characterized the Iguanidae as being "relatively phlegmatic"; perhaps they are better thought of as being quiescently vigilant.

Nonmating iguanas are relatively tolerant of the proximity of other iguanas. Typically, agonistic interactions are low in intensity, involve few displays, and occur only as they ascend the sleeping trees. They exhibited no defense of territories or other exclusive use areas. Their mild protests to being passed by another iguana along a branch did not extend to defense of a specific perch. Once an iguana had passed another, the two resumed a relaxed posture and showed no tendency to challenge each other. Suitable perches did not seem to be limiting.

Two lines of evidence suggest that headbobs often were given for a purpose other than winning 


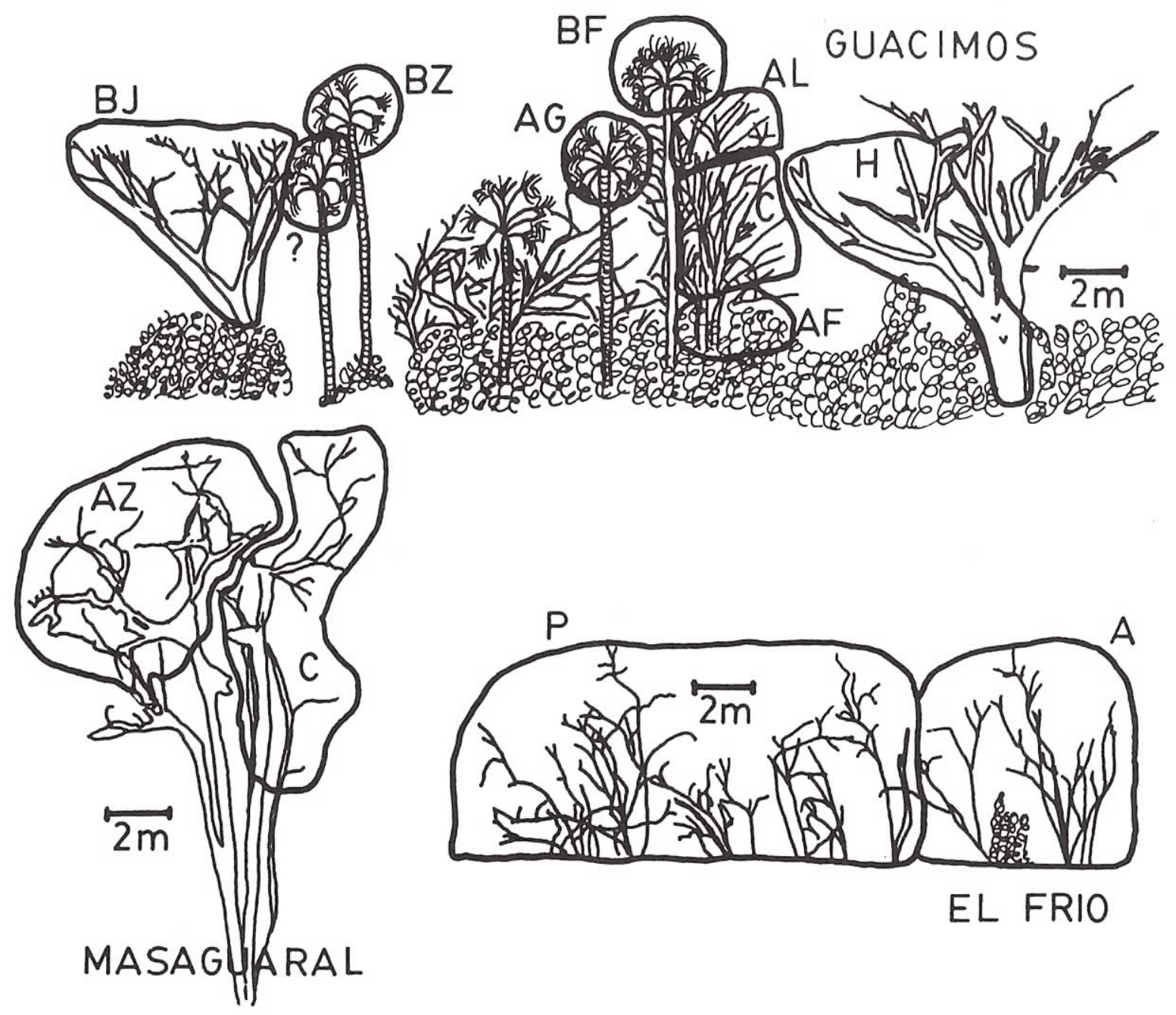

Figure 1. The study sites showing modal territory boundaries (males identified by letter codes). Each of the trees illustrated was approximately cylindrical and most projected out over the adjacent shoreline during the late dry and early wet seasons. During the late wet and early dry (mating) seasons the water rose and submerged the tree bases. The tree, including the territory of male $\mathrm{H}$ at Guacimos, was monitored continuously during the copulation season.

the interaction immediately at hand: (1) the overall lack of association between displays and success in interactions, and (2) the frequent display of headbobs after the iguanas had separated following an interaction (see "Female Dominance Relations").

The iguanas' tendency to sleep in a head up posture and bask in a head down posture may have a physiological basis. Clark and Gillingham (1990) argued that the head up sleeping posture adopted by two species of Anolis maximized nocturnal vigilance by keeping the anoles' heads toward the limb base, thereby expediting detection of climbing predators. This rationale is not directly applicable to the pattern of sleep postures in iguanas, as igua- nas on horizontal perches more often slept with their heads pointing away from the limb base.

Although nearly all iguanas slept in a horizontal or head up posture, most basked horizontally or with the head down. Head down basking might facilitate warming of the head and increase early morning motor coordination. Smaller iguanas can warm up faster than larger animals while basking, which presumably accounts for their leaving the sleeping tree sooner and returning later than the larger adults.

The density of iguanas in the Guacimos study area was higher than reported in Central America (Dugan, 1980:32-37; Van Devender, 1982). 
Density is known to affect social interactions; for example, territorial animals may shift to a hierarchy at sufficiently high densities (Brattstrom, 1974; Wilson, 1975). However, density did not appear to influence the behavior of nonbreeding iguanas, as the behavior at all sites was similar.

The lower site fidelity of females compared to males is consistent with Dugan's (1982b) observation that female home ranges were larger than those of males year round. Dugan suggested that the males may be maintaining residence status in an area that will be defended during the mating season. The higher number of females present at all times of year suggests that mortality may be higher among adult males. This was the case among roadkilled iguanas reported by Rodda (1990); the excess deaths of males (largely peripheral males) occurred during the mating season (see also Harris, 1982).

\section{General Mating Behavior \\ Results}

Male Hierarchy Formation. - The first event of the mating season was the gradual emer- gence of a male dominance hierarchy. Initially, males distorted their daily movements so as to avoid the immediate neighborhood of larger males. This was accompanied by an increase in the frequency or of headbob displays.

In these Venezuelan populations, the males did not develop a facial/mandibular reddening, as is characteristic of mating iguanas elsewhere (Dugan, 1980:31). In addition, males in the study areas did not acquire the tan, orange, or gold body color often found in Central America (Swanson, 1950; Alvarez del Toro, 1982:85; Fitch and Henderson, 1977).

TERRITORY FORMATION. - The year-round home ranges of the males I observed often contained several sites that eventually would become mating territories. Thus, territory formation involved both the selection of a mating territory and the establishment of defended boundaries for the chosen site. In the beginning of November, territorial defense was intermittent; a male would display for a few hours or days and then abruptly abandon an uncontested territory to try elsewhere. Often a

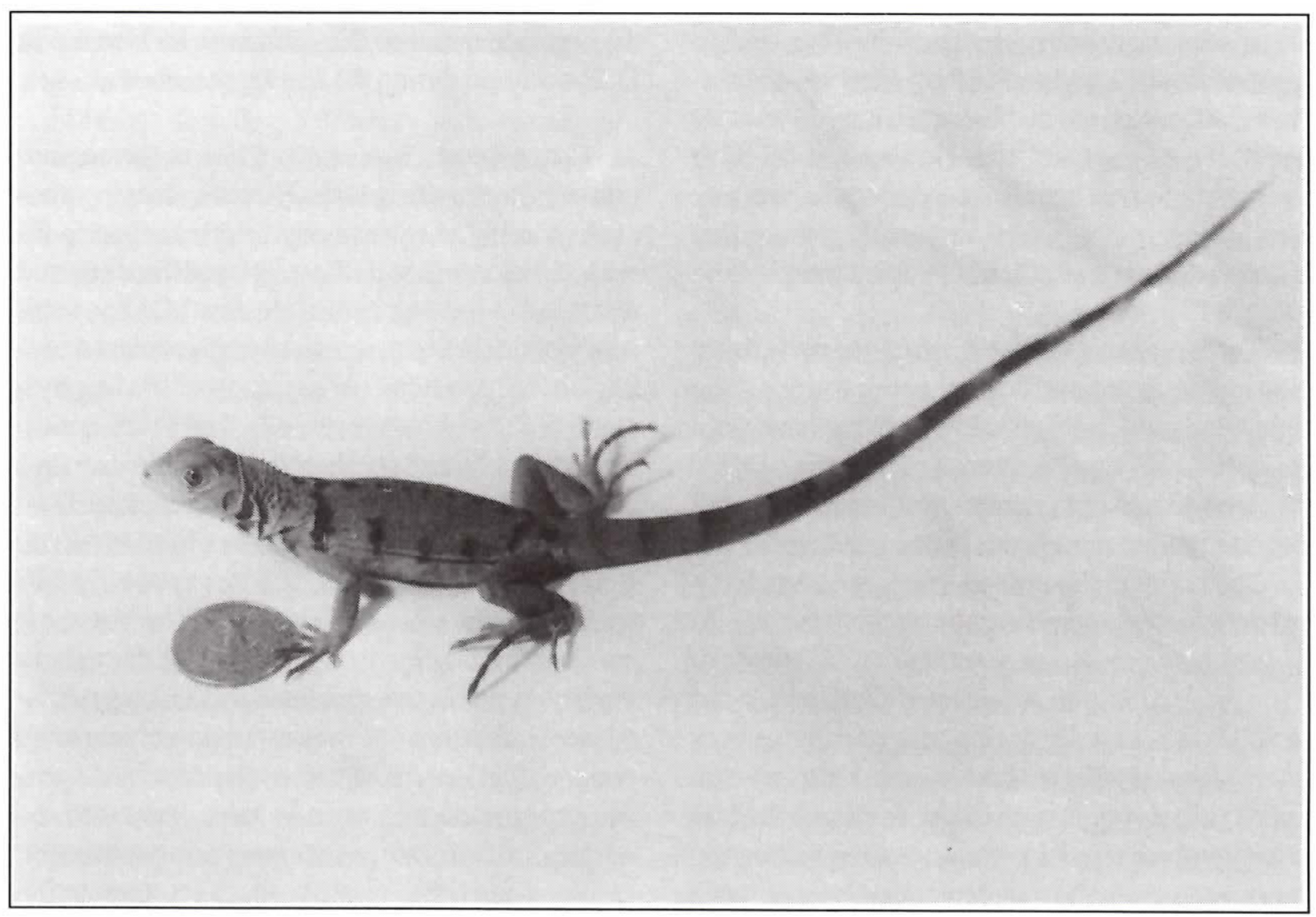

Two month old hatchling, Iguana iguana. Photography: Ron Harrod 
male would defend a territory for a few hours after dawn and before dusk (when the largest number of females were present), but not at other times of day. Territories were most often abandoned when few females were present. Territories tended to be established around the highest concentrations of females ("hot spots"). Surprisingly, some males at Guacimos continued to try to establish territories until nearly the end of the copulation season. Usually, no females would enter such a late territory and all of the very late territories were abandoned after a few days of unsuccessful displaying. In one case at Guacimos, however, part of a highly successful males' territory was usurped by a newly territorial male about $1 / 3$ of the way through the copulation season. In contrast to the unstable territorial boundaries at Guacimos, only two major changes in territory were noted at the two other sites in two years. In one case, a male at Masaguaral lost several of its foreclaws, presumably due to an injury suffered in intermale combat. As it became unable to reliably climb smooth-barked trees, it was no longer able to defend its entire territory. The abandoned part of its territory vas then incorporated into the adjacent male's territory. The following year the same male, still without use of some of its foreclaws, attempted to establish a territory in another tree at the Masaguaral site. However, it failed to attract any females and it abandoned the territory after a few days. Only very minor boundary changes occurred after territory formation in both years at El Frio.

The longest male: male interactions occurred in November, as territories were being formed. One fight, qualitatively similar to those that have been described for captive iguanas (Peracca, 1891), involved $45 \mathrm{~min}$ of vigorous wrestling and biting of extremities, but most fights lasted less than $30 \mathrm{sec}$.

Territorial males ceased foraging once territorial defense was maintained throughout the day. At El Frio both territories contained a few leaves of Nectandra pichurum, a preferred food, which one male ate occasionally during long pauses between interactions. However, this male ate little and continued to lose weight noticeably. Territorial defense often involved regular patrolling of the mating territory, presumably to intercept intruding males and to court females.
As territories became established and small males were excluded, females began to aggregate in the territories of the largest males. In the territory of male $\mathrm{H}$ at Guacimos, little change in female density occurred following territory establishment by the area's second largest male. The tree that became H's territory was heavily used by females prior to establishment of territories.

Small individuals of both sexes generally were excluded from preferred mating territories. As the territorial boundaries solidified, female use of the territories stabilized, with a high percentage of females returning to the same territory in which they spent the previous night. Some small males that did not display or remain in a territory during the day nonetheless often slept within another male's territory, arriving late and leaving early. The resident males did not attack or chase these small males. High numbers of females combined with the exclusion of small males during the middle of the day produced an elevated female:male territory sex ratio, which I term the operational sex ratio or OSR (cf., Emlen and Oring, 1977). The presence of small males reduced the OSR at dawn and dusk during the copulation season. Nevertheless, an increase in OSR occurred during the mating season at all sites.

Copulation Season. - Prior to the copulation season, female iguanas left their sleeping trees each morning. As their body cavities began to fill with developing ova, they stopped feeding and remained in the tree during the day. Midday occupancy of territories coincided with the onset of copulation, but preceded the cessation of feeding by a mean of $7.5+4.1$ days $(\mathrm{N}=7)$. The study territories were selected for their leaflessness and thus females moving into these territories may have been subjected to greater midday insolation (cf. Beuchat, 1988). However, females in heavily foliated territories were observed to follow the same pattern of remaining in their territories throughout the day. Females that remained in a mating territory were subjected to fewer mounting attempts by peripheral males. However, as the copulation season progressed, peripheral males increased the number of their intrusions into mating territories.

At Guacimos (1983), the first copulation attempt and first copulation occurred on 30 
November. At Masaguaral (1982), the first observed copulation attempt was on 19 November and the first observed copulation was on 20 November. At Guacimos, the territorial male obtained most of the copulations that occurred during the first half of the copulation season (Figure 2).

Once a territory was established, the roles of mature males fell into three classes: pseudofemale, peripheral, and territorial. Pseudofemales were small adult males that behaved as females. Generally they did not display, attempt to copulate, nor did they spend their days at the periphery of another male's territory, intruding when possible. Small males regardless of social status gave very few headbobs, whereas pseudofemales were conspicuously undemonstrative even for small iguanas. I saw pseudofemale behavior in only two situations: (1) at Masaguaral in 1982, a pseudofemale habitually occupied a tiny side branch off the trunk of the largest tree (Figure 1), at a place just below the major branching of the crown, where the territorial male normally perched; and (2) in several territories, pseudofemales entered the territory just before dusk and were the first to leave in the morning. On several occasions large or medium males attempted to mount such pseudofemales at dusk, but the pseudofemales fled. I believe that
- pseudofemales often were mistaken for females by other iguanas of both sexes.

The distinctive feature of peripheral males was their characteristic location (at the edge of a territory) and their repeated attempts to force copulations, either by a transient foray into a territory or by intercepting a female outside a territory. For the first half of the copulation season, females would occasionally leave a territory to feed, at which time they would be attacked by peripheral males. At least three times at Guacimos, a female who left her territory had to struggle to evade the three peripheral males that had simultaneously mounted her. Peripheral males displayed more often than the average small male (peripheral or pseudofemale), but not as often as an average territorial male. Many peripheral males were medium in size, but all sizes except the very largest were represented.

Territorial male behavior consisted primarily of territory patrolling, presumably in search of intruding males and receptive females. Territorial males reacted cautiously to most intruders, headbobbing and slowly approaching until near the intruder or until the intruder fled. However, territorial males seemed to recognize some individual iguanas at a distance; frequently a territorial male would move at near maximal speed toward an intruding male, which almost inevitably ran or

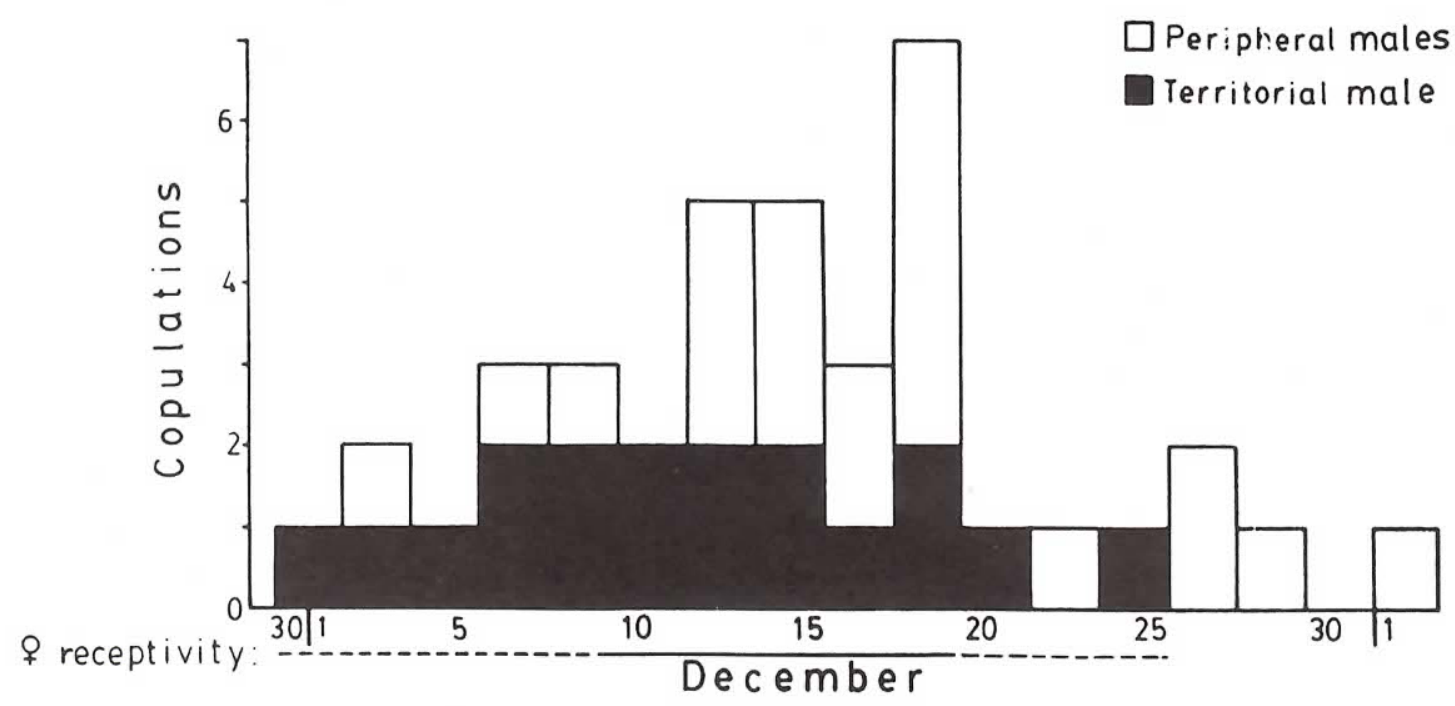

FIGURE 2. Copulation activity by date for Guacimos. The dashed tine below the abscissa indicates that a single unusual female was receptive on these dates (see text); the seven other resident females were receptive during the period marked by a solid line. 


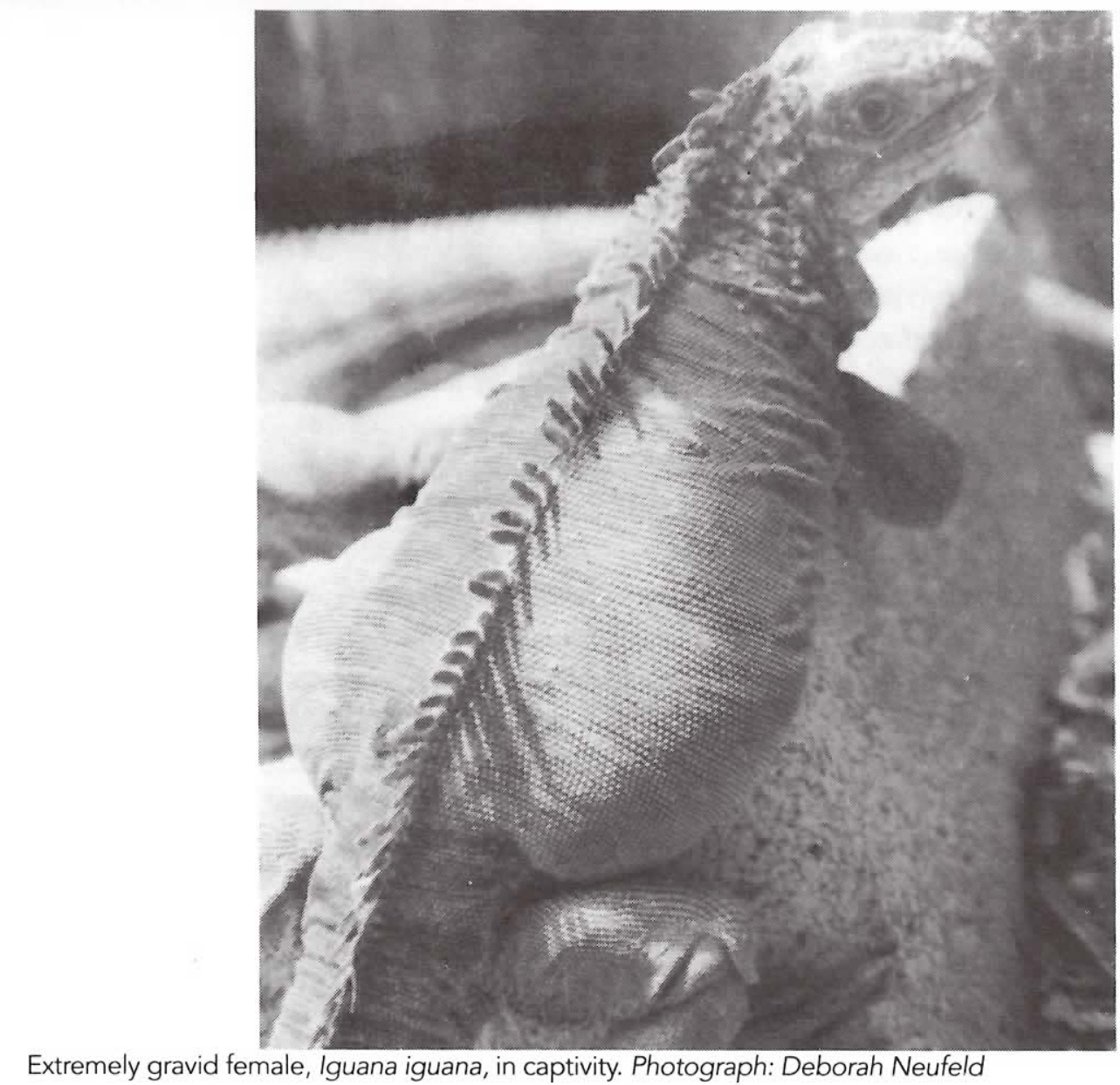

jumped out of the tree. In contrast, the arrival of a resident female would ordinarily evoke no more than a headbob. In 2 of 5 territories, the dominant male circled the periphery of his territory on a regular basis, taking 45-90 min for a circuit. In another 2 of these 5 territories the territory lacked circumferential branches that would permit patrolling along a circuit. The intensively monitored male at Guacimos so often interrupted his circuit to repel the frequent intrusions of peripheral males that no regular circuit was apparent.

While patrolling, a territorial male would approach each of his females. The deliberate approach to females seemed to be the same as the deliberate approach given by territorial males to unfamiliar iguanas. In particular, I observed no distinctive headbob associated with courtship; the shudder bob associated with courtship described by Dugan (1982a) occurred in a wide variety of high intensity contexts. Males gave shudder bobs (= vibratory head nodding, Distel and Veazey, 1982; or low-frequency head bobbing, Müller, 1972) more often than did females, but both sexes gave them in high intensity interactions with both males and females.
Female responses to approaches ranged from no overt reaction to vigorous biting, fleeing, and headbobbing. The no-reaction option was rare and usually resulted in a copulation attempt. However, only 30 of 248 copulation attempts at Guacimos were preceded by the female responding passively to a male approach. A small but unquantified number of passive responses occurred that did not progress to a copulation attempt (usually interrupted by a simultaneous peripheral male intrusion). Nevertheless, the total number of passive responses was a tiny fraction of the 657 approaches recorded for resident females while intruding males were absent at Guacimos.

Female rejection behaviors included waving one leg while lying down, arching or lashing her tail (if approached from the rear), headbobbing, walking away, facing, running away, and biting the male, generally in the face. Interpreting the passive responses as evidence of behavioral receptivity, and the range of dates on which passively received copulation attempts occurred as the window of receptivity for the six nearly continuously observed females at Guacimos ( $n=25$ passive responses). the six were receptive for $27,0,8,1,5$, and 1 days. 
The fernale that was receptive for 27 days, $\mathrm{AH}$, was aberrant in every measure of female reproductive performance; she accepted all males indiscriminately (both territorial and peripheral) over a span of dates $50 \%$ longer than the receptive seasons of all the other females combined. Captive iguanas arc receptive for periods of about 1 week (Braunwalder, 1979; Putz, 1982). Excluding AH and including three other females that were quantifiably receptive, female receptivity was brief and relatively synchronous. Receptivity for all eight females occurred in the period from 30 November to 19 December; seven of these were receptive during only 11 days: 9-19 December. Four were receptive simultaneously on 11 December.

All of the copulations performed by $\mathrm{H}$, the male in the intensively monitored territory, were observed. At the beginning (30 Nov-5 Dec) and end (20-24 Dec) of the copulation season, male H's copulations occurred on alternate days. During the middle of the copulation season (6-19 Dec, except $16 \mathrm{Dec})$, male $\mathrm{H}$ copulated once daily. On four of the five skipped days at the beginning and end of the season male H everted his hemipenes and exuded a white, viscous liquid. His choice of right or left hemipenis did not differ from a random sequence (Runs test: $r=10 ; \mathrm{n}=7,9 ; 0.05<P<0.95$ ). Comparable data are not available for any other site or male, although it is noteworthy that on one day at El Frio male P copulated shortly after dawn and then again shortly before dusk. This was the only observed exception (out of 55 copulations observed at all sites) to the generalization that iguanas copulate no more than once per day.

The dawn and dusk copulations of male $\mathrm{P}$ also were anomalous in their time of occurrence. Most territorial male copulations occurred around midday copulations by territorial males were more concentrated in time $(F=3.90 ; \mathrm{df}=21,18 ; P=0.002)$ than were those of the more opportunistic intruders. The difference is also significant for copulation attempts $(F=2.57$; df $=202,43 ; P<0.0012)$, indicating that the peripheral males were attempting and obtaining copulations at a wider range of times of day. This might be related to an apparent once-aday limitation on copulations. If males stopped attempting to copulate after their first copulation of the day and if the territorial males were able to obtain a copulation after basking every day, their copulations would be relatively concentrated at midday.

Did territorial males stop attempting to copulate after their first success of a day? I identified 12 precopulatory intervals of about $2 \mathrm{~h}$ that could be paired with 12 identical but postcopulatory timesof-day for dates that were only one or a few days earlier or later (dates and times were matched to control for seasonal or daily/temperature changes in ardor). For example, the number of a male's copulation attempts between $1000 \mathrm{~h}$ and $1200 \mathrm{~h}$ on a day when the male copulated at $1200 \mathrm{~h}$ would be compared to the number of his copulation attempts between $1000 \mathrm{~h}$ and $1200 \mathrm{~h}$ a few days later when he copulated at $1000 \mathrm{~h}$. No copulation attempts occurred in the intervals after a success, whereas significantly more (mean $0.83+0.21$ ) occurred in the intervals that were not preceded by a copulation (Wilcoxon matched-pairs signed-rank $T=0$; $n=61 ; P=0.025)$. However, iguanas may be unavoidably refractory even after a failed copulation attempt. If this were so one would expect a similar reduction in copulation attempts by peripheral males. For the two peripheral males for whom adequate data exist, no evidence of a refractory period was detectable in terms of number of copulation attempts (Wilcoxon $T=9.5 ; n=6 ; P>>0.05$ ), number of intrusions (Wilcoxon $T=17.5 ; \mathrm{n}=8$; $P>>0.05$ ), or latency to next copulation attempt (Mann Whitney $U=12 ; n=5,6 ; \mathrm{P}=0.33$ ). Unlike the territorial males, peripheral males attempted to copulate after a successful copulation. Although no peripheral males were observed to succeed in obtaining more than one copulation per day, the peripheral males very low success rate during any copulation attempt (see following section) would render two successes on a single day improbable. Although the territorial male stopped copulation attempts after a success, there was no reduction in his locomotor activity (mean increase $=1.9 \mathrm{~m} / \mathrm{h}$ ) or approaches to resident females (mean increase 0.015 approaches $/ \mathrm{h}$ ). This implies that the male may have been invigorated and was surely not exhausted by copulation, and that even if approaches to females are equivalent to "courtship," they are not necessarily a preliminary to copulation. Close approaches to females may be an unavoidable correlate of territorial patrolling. 
The average copulation of the territorial male at Guacimos lasted $9.0 \mathrm{~min}, 2 \mathrm{~min}$ longer than that of the average peripheral male copulation $(t=1.72$; $\mathrm{df}=31 ; P=0.047)$. This difference was significant even if comparing only the uninterrupted copulations of each male type $(t=2.37 ; \mathrm{df}=24$; $P=0.013)$. The durations of copulations among all iguanas in my sample did not deviate significantly from those reported by Dugan (1980:79; 1982b) ( $t=1.32 ; \mathrm{df}=64 ; P=0.19)$, although my sample probably includes more peripheral male copulations, which bring the means closer together. Uninterrupted territorial male copulations at Guacimos were significantly longer than those in Dugan's sample $(t=3.05 ; \mathrm{df}=37 ; P=0.0042)$.

During copulations, both territorial and peripheral males exhibited low-amplitude spasmodic head twitches that occurred synchronously with even lower amplitude tail base movements and abdominal contractions (cf. head movements reported by Braunwalder, 1979; Putz, 1982). Twitch rates varied from 0 to 48 beats per minute (bpm), with the mean of 33 nonzero measurements on males being $21.9(\mathrm{SD}=11.9)$. Three measured means for entire single copulations were 12.7, 20.7, and $20.8 \mathrm{bpm}$.

My impression is that the contractions represented sperm transfer contractions. For the 12 copulations for which adequate data exist, the contractions began within a few seconds of intromission and continued for an average of $75 \%$ of the total copulation time. On three occasions white viscous fluid was visibly emanating from a hemipenis when a copulation was broken up while the male was still contracting. Cessation of pulses was a good predictor that uncoupling was imminent.

Some females changed territories during the copulation season, but most females became extremely consistent in their choice of sleeping trees. Inconsistent females generally were (1) small, (2) harassed by the larger females, and (3) inclined to leave the tree early and return late. Most consistent females remained in the tree throughout the day. I termed the latter "residents." At Guacimos 11 females were residents in the intensively monitored territory for some or all of the copulation season. The territorial male copulated with eight of these, all of whom had been residents since the beginning or almost the beginning of the mating season. Of these eight, one of the two largest

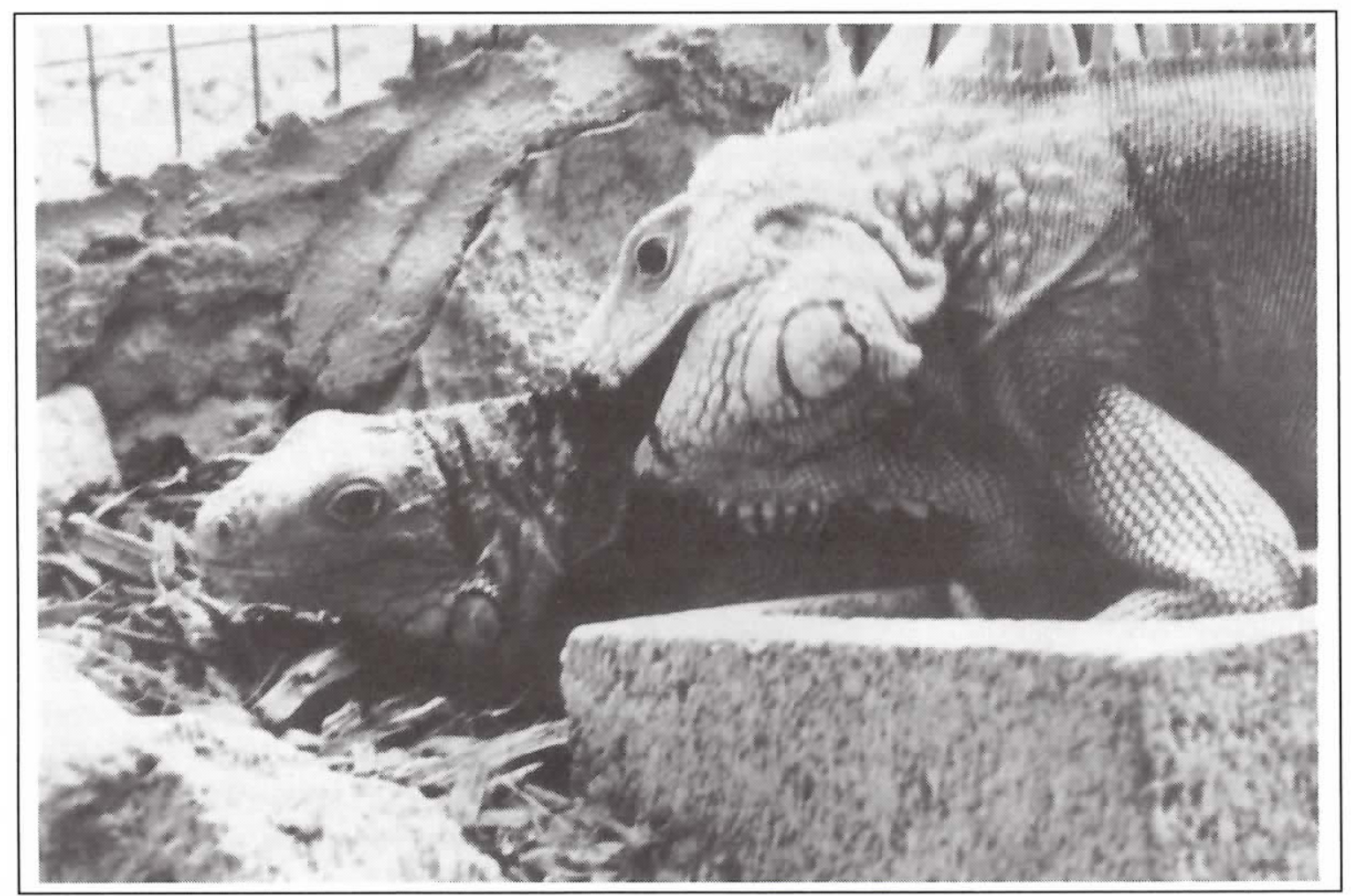

16 year old male, Iguana iguana, in precopulatory embrace. Photography: $R$. W. Ehrig 
females in the territory left to become a resident in an adjacent territory during the copulation season. Her departure as a resident followed immediately after losing an encounter with the other largest female, with whom she had previously interacted amicably. She departed (as a resident) before being inseminated by the territorial male, but she returned for a brief daytime visit on the following day, copulated with the territorial male, and then left permanently (i.e., did not enter the tree again during the mating season).

Three females became residents after the beginning of the copulation season. Two of these had copulated elsewhere shortly before changing territories. One was the largest female seen at any site (of 166 total), and just before switching she had copulated with the largest male. The resident male in her new territory mounted this female five times, but each time she resisted violently and escaped. She left the territory as a resident after five days, but returned irregularly thereafter. My impression was that she moved to the intensively monitored territory and then left the territory to find a new refuge with less harassment by males. The other two late-arriving female residents were not mounted by the resident male.

Similar female behavior was seen at Masaguaral. A major difference was That five of the nine females that were residents in the clump of four study trees (two territories) at Masaguaral switched territories (but not clump) several times; one switched at least 12 times. The Masaguaral data established only a minimum number of switches for these five females, but the mean of these minima was 6.2. The female that switched at least 12 times copulated with both territorial males. In the female dominance hierarchy this female ranked third from the top (out of 14 (including all females in area)). However, high rank was not associated with switching, as the nonswitching females were ranked $1,2,4$, and 8 .

Twenty females were residents for at least part of the copulation season at Guacimos in 1983 $(n=11)$ or Masaguaral in $1982(n=9)$. Of these, seven were observed to copulate with at least two different males; seven more probably copulated with multiple males, based on the observed pattern of their territory switches; and five probably (two definitely) were not multiply mated.

For the six females at Guacimos whose mating behavior was completely monitored, the average number of copulations per female was $4.8+4.7$, but this value is grossly distorted by the one aberrant female, $\mathrm{AH}$, that copulated 15 times. Excluding her, the average is much lower and less variable $(3.0+1.4)$

All mating behaviors dropped abruptly in vigor and frequency around 18 December 1982 at Masaguaral and 19 December 1983 at Guacimos. Displays waned, locomotion dropped, male aggression decreased noticeably, female belligerence peaked (then apparently dropped sharply a few weeks later), male territory defense became irregular, and territorial males resumed feeding. Most importantly, the frequency of copulations at Guacimos dropped sharply from nine (17-19 Dec) to one (20-22 Dec), with that one involving the aberrant female $\mathrm{AH}$. Excluding $\mathrm{AH}$ there was only one copulation after $19 \mathrm{Dec}$, and that was a forced copulation of a cripple (broken foreleg). Four females from a nearby area were inspected for reproductive condition 15-22 December 1983. Three were on the threshold of ovulating (follicles $>20 \mathrm{~mm}$ dia.) and the fourth had begun ovulating.

Mating Success. - To evaluate the relative reproductive success of males of different roles or size.; one would prefer representative observations of the entire male population. Unfortunately, it was difficult to keep small males in view. They appeared to avoid reproductively active areas and none were seen to copulate. This is especially noteworthy as copulations were conspicuous owing to (1) the prominent perches usually occupied by copulating iguanas, (2) the violent physical grappling associated with most of the observed copulations, and (3) the relatively long duration of copulations. Thus, the successful males were easily identified and these individuals could be apportioned among the size classes and roles they represented.

The best size class data are for Guacimos. I based the proportions of the various size classes on the mix found among known size animals: $48 \%$ small, 26\% medium, and $26 \%$ large. No pseudofemales were observed to attempt a copulation at Guacimos, so it is possible that pseudofemale 
behavior in this population served only to avoid the attacks of larger males. Of the males that slept in either the intensively monitored territory or an adjacent undefended area during the copulation season, an average of $1.0(16 \%)$ per night was a territorial male, $2.6(43 \%)$ were peripheral males, and 2.4 ( $40 \%)$ were the pseudofemales not seen to attempt mating (although of a size believed to be physiologically competent, based on dissection of 57 roadkills: Rodda, 1991).

Mating success is usually measured by the number of copulations obtained. However, because females under continuous observation copulated from 1 to 15 times, it seems reasonable to treat one female's sole copulation as being much more significant than would be one of another female's 15 copulations. Reproductive success has been apportioned using three alternative hypotheses for the form that sperm competition might take. Under the mix hypothesis all matings were counted as fertilizing $1 / n$ of each clutch, where $n$ is the number of copulations each female received. Under the firstprecedence hypothesis the first copulation was assumed to fertilize all of that female's eggs; under the last-precedence hypothesis the last fertilization before 23 December (a likely ovulation date) was assumed to fertilize all eggs. For these computa- tions it was necessary to know all of each female's copulations. Thus, only the six females under continuous observation were used. Based on these computations it would appear that there is an enormous advantage to being a large territorial male, and the discrepancy between classes is greatest if early inseminations take precedence in obtaining fertilizations.

Qualitatively, this finding was observed in every territory, but the total success of peripheral males was higher in some territories and lower or negligible in others. The two key variables were access to the territory and the density of females. Isolated palm trees were almost impossible for a peripheral male to invade, whereas territories with multiple entry points were less defensible. Interlocking canopies, multiple trunks, and multiple territories within a tree (e.g., Guacimos, C in Figure 1) promoted the success of peripheral males. At El Frio, the territory of male $\mathrm{P}$ had almost unlimited entrance routes, but the low density of females and the superb visibility in the nearly leafless territory made it difficult for an invading peripheral male to escape detection.

CONTINUED IN NEXT ISSUE...

\section{IgUANA Rescue Group UpDATE}

The Iguana Rescue Group of central Florida has continued rescue, rehabilitation, and placement of iguanas including some out of state. To date over 35 iguanas have been placed.

\section{The Iguana Rescue Group}

\section{Florida (Central-North-Gulf Coast) Contact}

Deborah Neufeld

P.O. Box 423332

Kissimmee, Florida 34742

Janet and Dennis Truse

Lori Sandlin

(407) 846-6976

(407) 877-3024

\section{South Florida and Elsewhere}

IIS

(305) 872-9811

\section{Tennessee}

Memphis Iguana Rescue Group

Gina Turri

3348 Powell

Memphis, TN 38122

(901) 323-5563 